\title{
Logística reversa frente à Política Nacional de Resíduos Sólidos nas MPE's do setor de metalurgia na Região de Jundiaí
}

\author{
Djair Picchiai ${ }^{1}$ \\ Ulisses Tavares ${ }^{2}$
}

\begin{abstract}
Resumo: O objetivo deste trabalho é uma análise do papel da logística reversa nas micro e pequenas empresas - MPEs - do setor de metalurgia na Região de Jundiaí, estado de São Paulo. Com a vigência da Lei no 12.305, de 2 de agosto de 2010, e do Decreto 7404/2010, que regulamenta a Política Nacional de Resíduos Sólidos - PNRS, a logística reversa começou a chamar mais atenção das MPEs, as quais enfrentam poucas barreiras de aplicação. Por logística reversa entende-se a gestão integrada do retorno de produtos com o processo de produção da empresa, visando ao descarte ecologicamente correto de seus produtos ao final de seu ciclo de vida. Para o estudo, utilizou-se dois métodos de coleta de dados e de informações. O primeiro constituiu-se de uma pesquisa bibliográfica, realizada por consulta a livros, dissertações, teses, artigos de revistas científicas e de congressos (CASTRO et al., 2015). O segundo foi uma entrevista estruturada com os gestores responsáveis pelo setor de logística reversa das respectivas empresas. As MPEs da Região de Jundiaí sabem que as práticas de logística reversa são de grande importância para as organizações, no entanto têm dificuldades na implantação dessa logística, uma vez que necessitam de projetos específicos, com altos custos financeiros (RODRIGUEZ et al, 2015). As parcerias público-privadas passam a ser soluções para o cumprimento desses desafios.
\end{abstract}

Palavras-chave: Logística Reversa. Política Nacional de Resíduos Sólidos. Metalurgia. Gestão de Resíduos Sólidos Industriais. Sustentabilidade.

\begin{abstract}
This article aims to analyze the role of reverse logistics in Micro and Small Enterprises - MSEs metallurgy sector in the region of Jundiaí, São Paulo. With the enactment of Law No. 12.305, of August 2, 2010, and Decree 7404/2010, which regulates the National Policy on Solid Waste - PNRS, reverse logistics begins to be observed more closely by MSEs, which have some implementation barriers. For reverse logistics means the integrated management of returning products to the company's production process to the environmentally friendly disposal of their products at the end of their life cycle. For the study used two methods of collecting data and information. The first consisted of a literature survey, conducted by consulting books, theses, dissertations, journal articles and conference (Castro et al, 2015). The second was a structured interview with the managers responsible for the reverse logistics industry of their respective companies. It can be seen from the research that the MSEs of the Jundiai region know that reverse logistics practices are of great importance for organizations, but they have difficulties in the implementation of reverse logistics, as it requires specific projects with high costs financial. Public-private partnerships are now solutions to meet these challenges.
\end{abstract}

Keywords: Reverse Logistics. National Solid Waste Policy. Metallurgy. Industrial Solid Waste Management. Sustainability.

\footnotetext{
${ }^{1}$ Doutor em Administração de Empresas. Professor do Programa de Pós-Graduação em Administração da FACCAMP e da Fundação Getúlio Vargas (SP). djair.picchiai@fgv.br

${ }^{2}$ Mestre em Administração. Professor da UNIESP. ulisses_tsilva@ig.com.br
} 


\section{Introdução}

A logística reversa desempenha um papel de fundamental importância na operação da cadeia de suprimentos. Inicialmente, o foco principal era o retorno de materiais para reciclagem, mas, com o tempo, o tema foi recebendo novas abordagens. A mais perceptível é o reconhecimento de novas oportunidades competitivas, oriundas da redução de custos e de relacionamentos empresariais. Encontramos também um forte apelo em relação à defesa da imagem corporativa e da responsabilidade ética empresarial, nada mais que novas perspectivas da atual logística reversa.

Em 2 de agosto de 2010, entrou em vigor a Lei no 12.305, que trata da Política Nacional de Resíduos Sólidos (BRASIL, 2010). O Brasil está vivendo um momento diferenciado, buscando um desenvolvimento da economia que respeita o meio ambiente. Para tanto, é preciso incentivar a responsabilidade social e aplicar, dessa maneira, a sustentabilidade na prática (THODE FILHO et al., 2015). Com a vigência da atual legislação, o rigor quanto ao descarte de materiais e produtos inservíveis faz com que as empresas sejam obrigadas a desenvolver estratégias para a logística direta e para a logística reversa, especificando como deve ser a destinação adequada dos resíduos gerados no processo produtivo.

De acordo com a Associação Brasileira de Empresas de Limpeza Pública e Resíduos Especiais (ABRELPE), o Brasil produziu, aproximadamente, 78,6 milhões de resíduos sólidos urbanos em 2014, quantia 2,9 \% superior à quantia total gerada em 2013. Em comparação, a população brasileira, no mesmo período, apresentou crescimento inferior a $1,0 \%$. As projeções do IBGE (2008) indicam uma população de 215 milhões em 2050.

Figura 1 - Geração de Resíduos Sólidos Urbanos

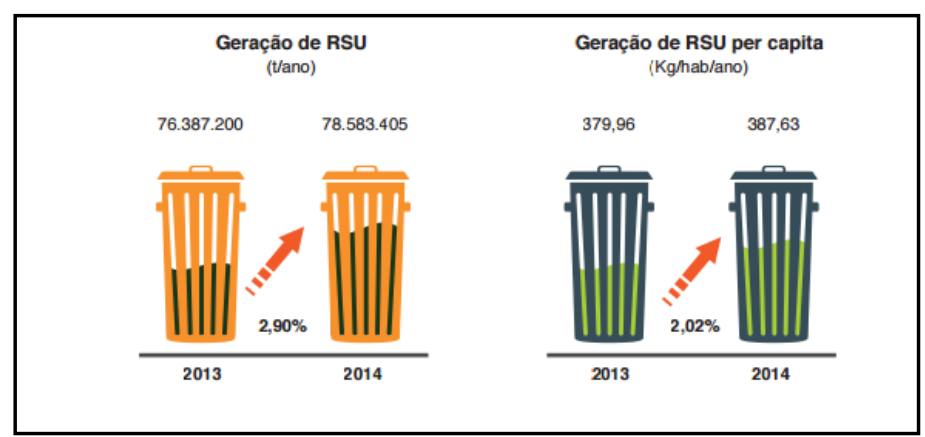

Fontes: Pesquisas ABRELPE 2013 e 2014 e IBGE.

(contagem da população 2013 e Censo 2010) 
Os processos produtivos empresariais, em grande parte, causam consequências para a sociedade e o meio ambiente, cuja preservação gera uma maior preocupação. Para que a empresa se mantenha no mercado de forma competitiva, é necessário que haja a incorporação de uma estratégia de sustentabilidade da gestão.

A integração entre as empresas e o meio ambiente denomina-se de "gestão ambiental" (DOURADO; SAIANI; TONETO, 2014), e, segundo Wu e Dunn (apud DOURADO; SAIANI; TONETO, 2014), essa gestão será ineficiente sem o apoio em atividades logísticas a fim de alcançar uma performance superior.

\subsection{Objetivo}

Procurou-se estudar a importância da logística reversa no processo de gerenciamento da cadeia de suprimentos no sentido de aumentar a competitividade, cumprir leis e preservar o meio ambiente.

Assim, o estudo vai analisar o desenvolvimento da aplicação da logística reversa no setor de metalurgia na Região de Jundiaí, com a finalidade de diagnosticar os efeitos da política de planejamento direcionada para a gestão de resíduos sólidos industriais nas micro e pequenas empresas do setor metalúrgico após a vigência da Política Nacional de Resíduos Sólidos.

\section{Metodologia}

O presente estudo foi realizado na em 58 MPEs da Região Administrativa de Jundiaí, que engloba sete municípios: Jundiaí, Cabreúva, Campo Limpo Paulista, Itupeva, Jarinu, Louveira e Várzea Paulista. Foram utilizados dois métodos de coleta de dados e de informações: primeiramente, constituiu-se de uma pesquisa bibliográfica, realizada por consulta a livros, dissertações, teses, artigos de revistas científicas e de congressos (CASTRO et al., 2015). O segundo foi uma entrevista estruturada com os gestores responsáveis pelo setor de logística reversa das respectivas empresas.

Para a realização de uma pesquisa científica, existe a necessidade de levantamento e coleta de dados. Conforme e Lakatos e Marconi (2009, p. 176), este procedimento pode ocorrer de diferentes formas, tais como: a) documentação indireta: pesquisa documental e 
pesquisa bibliográfica; b) documentação direta: pesquisa de campo, experimental e de laboratório; c) observação direta intensiva: observação e entrevista; d) observação direta extensiva: aplicação de questionário.

Quanto aos meios, a pesquisa será de campo e bibliográfica (VERGARA, 2000). De campo, pois os dados necessários foram obtidos pelo pesquisador no local do estudo; bibliográfica, uma vez que, nesta pesquisa, buscam-se referências em livros, artigos, revistas especializadas qualis.

\section{Fundamentação teórica}

$\mathrm{Na}$ fundamentação teórica, foram abordados os conceitos que envolvem a problematização, os objetivos e a justificativa do trabalho. Dessa forma, foram apresentados os princípios que tratam do tema: logística reversa; Política Nacional de Resíduos Sólidos e Gestão de Resíduos Sólidos; e sustentabilidade.

\subsection{Logística reversa}

A logística reversa é uma área da logística empresarial que tem a finalidade de gerenciar e operacionalizar o retorno de bens e materiais após sua venda e/ou consumo para o ponto de origem. Tem como objetivo principal a preservação do meio ambiente, atendendo aos princípios da sustentabilidade ambiental. É de fundamental importância para os gestores na tomada de decisões estratégicas das empresas, pois ela engloba desde a aquisição de matérias-primas até o consumo final, acompanhando o fluxo e as informações sobre estes produtos, com a finalidade de reduzir custos e promover uma diferença no atendimento das demandas, resultando em agregação de valor ao produto.

A diferença entre a logística empresarial e a reversa é o sentido do fluxo do produto. O da logística empresarial inicia no ponto de origem do produto, indo até o seu ponto de consumo; o da logística reversa, do ponto de consumo até a origem do produto. Um conceito mais amplo nesse contexto é o do ciclo de vida do produto (CVP), uma vez que a vida de um produto não acaba na entrega ao cliente, mas com o retorno ao ponto de 
origem, para que seja adequadamente descartado ou reprocessado (LACERDA apud DOURADO; SAIANI; TONETO, 2014).

A logística reversa trata da questão relacionada à recuperação de produtos resíduos de um modo geral, desde o ponto de consumo até o local de origem ou de disposição em local seguro. Neste contexto, trata de um tema bastante sensível e muito oportuno, pois é necessário realizar um descarte adequado para os resíduos, contribuindo, assim, com a preservação do meio ambiente, já que a formação de resíduos é intrínseca à maioria dos processos industriais. No Brasil, ainda é considerada uma novidade no universo dos resíduos sólidos, sendo, pois, importante ressaltar que, para a sua implantação efetiva, é imprescindível que haja investimento nessa área, a fim de que se possa proporcionar um diferencial competitivo em relação aos concorrentes.

Uma gestão responsável de resíduos pode trazer receitas ambientais que unem os recursos resultantes de vendas de subprodutos ou de materiais reciclados (CARVALHO; BARBIERI, 2013), ou mesmo de uma participação no ganho total, resultante da postura ambiental responsável (SANTOS; SILVA SOUZA; SOUZA apud ALTOÉ, VOESE, 2014). King et al. (2006) apresentam alternativa para a redução de resíduos, conforme a Figura 2.

Figura 2 - Alternativas para Redução de Resíduos

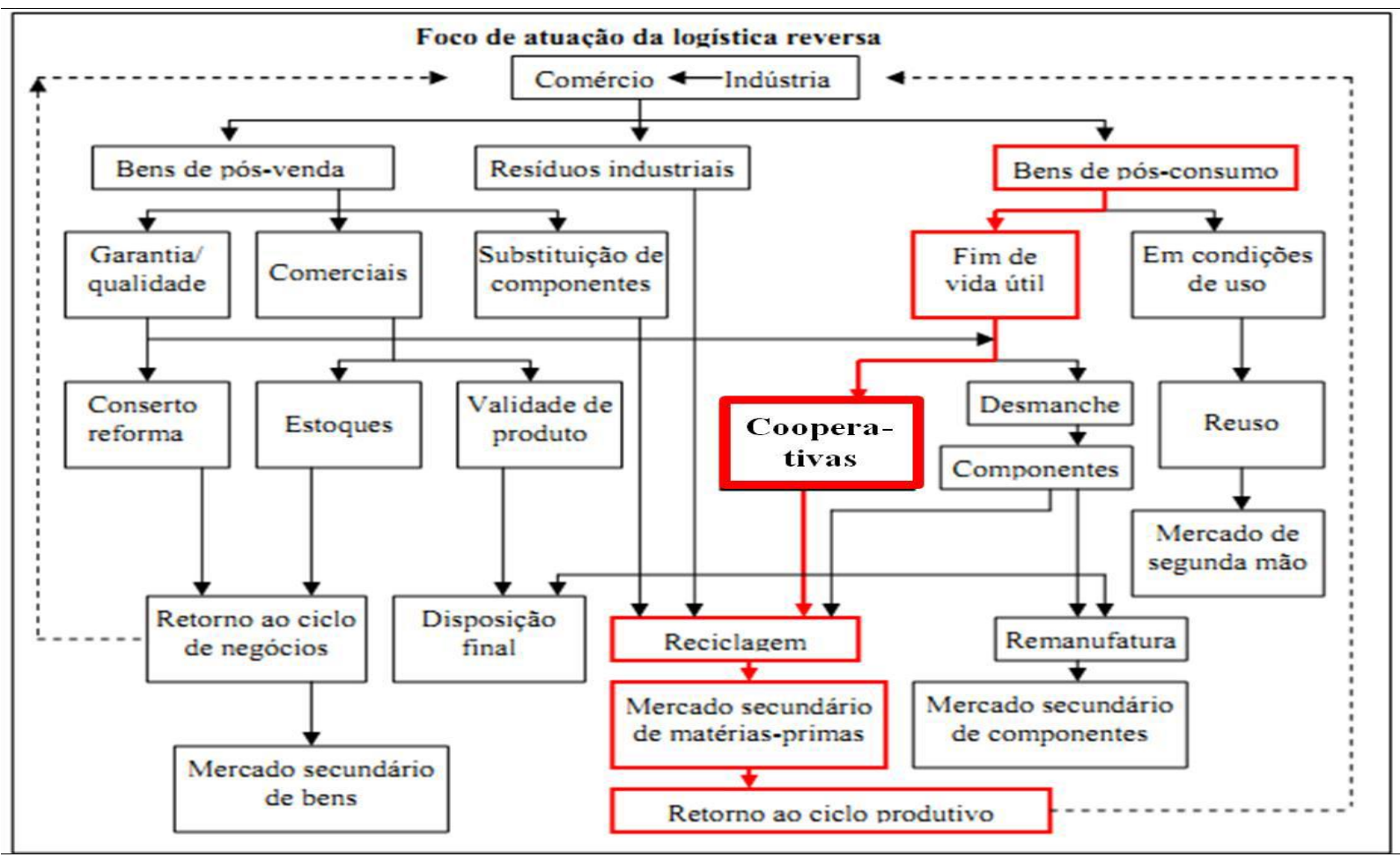

Fonte: King et al., 2006. 
O fluxo logístico reverso é comum para uma boa parte das empresas. Podemos citar como exemplo as siderúrgicas que usam como insumo de produção a sucata gerada por seus clientes, e, para isso, usam centros coletores de carga.

Nos Estados Unidos, os sistemas de logística reversa desenvolvidos para a indústria de aço representam um volume significativo, considerando as características desse setor industrial. Estima-se que 50 milhões de toneladas de sucata ferrosa são gerenciados a cada ano na América do Norte por meio dessas redes de logística reversa (JOHNSON, 1998). O sistema de reciclagem de sucata de metais ferrosos representa um significativo nível de atividade econômica, com receita estimada de US \$ 8 bilhões.

\subsubsection{Logística reversa de pós-venda}

A logística reversa de pós-venda tem como finalidade atuar no equacionamento e operacionalização do fluxo físico e das informações logísticas de bens de pós-vendas. Ela também trabalha com produtos sem uso ou com pouco uso, os quais retornam aos diferentes elos da cadeia de distribuição por vários motivos: erros de expedição, produtos consignados, excesso de estoque, giro baixo, produtos sazonais, produtos defeituosos, recall de produtos, validade expirada e produtos danificados durante o transporte.

Segundo Zimermann e Graeml (2003), são caracterizados como bens de pós-venda aqueles produtos com pouco ou nenhum uso, devolvidos pelo consumidor final. Neste caso, é necessário haver planejamento, operação e controle do fluxo físico e das informações logísticas correspondentes de bens de pós-venda (DA SILVA et al, 2014).

Conforme Resende (2004), o fluxo reverso de pós-venda origina-se em diferentes momentos da distribuição direta, ou seja, do consumidor final para o varejista, ou entre os membros da cadeia de distribuição direta. A destinação final dos produtos de pós-venda pode parar nos mercados secundários, nas reformas, nos desmanches, na reciclagem dos produtos e na disposição final.

As iniciativas que vêm sendo tomadas pelas empresas em relação à logística do pós-

venda trazem às empresas uma compensação em seus custos e, consequentemente, aumentam sua lucratividade, devido à agregação de valor ao produto, o que garante um diferencial competitivo para a empresa. 


\subsubsection{Logística reversa de pós-consumo}

Os produtos de pós-consumo referem-se àqueles que encerram sua vida útil e que podem ser enviados a destinos finais tradicionais, como a incineração ou aterros sanitários, ou retornar ao ciclo produtivo por meio de canais de desmanche, reciclagem e reúso, expandindo sua vida útil.

O objetivo econômico da implementação da logística reversa de pós-consumo pode ser entendido como a obtenção de resultados financeiros por meio de economias obtidas nas operações industriais, principalmente pelo aproveitamento de matérias-primas secundárias, provenientes dos canais reversos de reciclagem, ou de revalorizações mercadológicas nos canais reversos de reúso e manufatura.

Segundo (LEITE, 2003), logística reversa do pós-consumo é definida por sua “[...] cadeia de distribuição direta, possui uma estrutura própria de canal formada por empresas especializadas em suas diversas etapas, que formam o reverse supply chain". Os bens de pós-consumo são os produtos ou materiais constituintes, cujo prazo de vida útil chegou ao fim, sendo assim considerados impróprios para o consumo primário, ou seja, não podem ser comercializados em canais tradicionais de vendas.

Nesse contexto, pode-se dizer que a logística reversa de pós-consumo deve administrar não somente a entrega do produto ao cliente, mas também o seu retorno, direcionando-o para ser descartado ou reutilizado de forma correta. Dessa forma, a empresa estará contribuindo para um desenvolvimento sustentável, o qual vai refletir em vantagens competitivas para a instituição.

\subsection{Política Nacional de Resíduos Sólidos}

Com o crescimento constante da população, surge a necessidade de aumentar a industrialização de matérias-primas, transformando-as em produtos industrializados, situação essa que contribui para o aumento dos resíduos sólidos, os quais provocam impactos no meio ambiente e na qualidade de vida da população.

Com a vigência da Política Nacional de Resíduos Sólidos, que estabeleceu como instrumento de desenvolvimento econômico e social a implantação de sistemas de logística 
reversa, imputando a responsabilidade do pós-consumo aos fabricantes, importadores, distribuidores, comerciantes e consumidores, implantou-se a responsabilidade compartilhada.

A Lei no 12.305, de 2 de agosto de 2010, que institui a Política Nacional de Resíduos Sólidos (BRASIL, 2010), define como responsabilidade compartilhada o seguinte:

Art. 30 - É instituída a responsabilidade compartilhada pelo ciclo de vida dos produtos, a ser implementada de forma individualizada e encadeada, abrangendo os fabricantes, importadores, distribuidores e comerciantes, os consumidores e os titulares dos serviços públicos de limpeza urbana e de manejo de resíduos sólidos, consoante as atribuições e procedimentos previstos nesta seção.

A Política Nacional de Resíduos Sólidos trata não só da responsabilidade dos geradores e do poder público como também das diretrizes relativas à gestão integrada, ao gerenciamento de resíduos sólidos e aos instrumentos econômicos aplicáveis. Um ponto de grande importância na Política Nacional de Resíduos Sólidos é a responsabilidade compartilhada, que envolve ações conjuntas do poder público, do setor empresarial e da sociedade, com a finalidade de solucionar, ou mitigar os problemas relacionados aos resíduos sólidos. Determina também as obrigações individualizadas de cada gerador de resíduos sólidos, com a finalidade de reduzir os impactos ao meio ambiente e à saúde humana, a caminho de um consumo sustentável.

Conforme determinação da Política Nacional de Resíduos Sólidos (PNRS), em vigor desde 2010, a partir de 03 de agosto de 2014, o Brasil não poderia ter mais lixões a céu aberto em funcionamento. No entanto, houve a prorrogação dessa data, e ainda existem no Brasil cerca de 3.500 lixões ativos em todas as regiões brasileiras, o que representa um descumprimento da lei por 60,7\% dos municípios. A Confederação Nacional dos Municípios (CNM) já solicitou junto ao governo federal a prorrogação do prazo estipulado na legislação em vigor, com a alegação de que os municípios não tiveram nem tempo, nem receita suficiente para construir aterros sanitários e planos de coleta seletiva.

A Política Nacional de Resíduos Sólidos é uma ferramenta fundamental para fomentar o desenvolvimento sustentável no Brasil. Esta é um grande passo para que instituições, governo, empresas públicas e privadas e o cidadão comum lidem melhor com o lixo produzido, dando-lhe um destino mais adequado. 


\subsection{Resíduos Sólidos Industriais}

Os resíduos industriais são originados nas atividades dos diversos ramos da indústria, tais como o metalúrgico, o automotivo, o químico, o petroquímico, o de papelaria, o da indústria alimentícia, etc. O resíduo industrial é um dos maiores responsáveis pelas agressões ao meio ambiente.

Os resíduos gerados têm aumentado de volume e, caso não sejam bem gerenciados, vão contribuir na degradação do meio ambiente. Problemas relacionados com os resíduos sólidos são cada vez mais visíveis e crescentes, os quais contribuem para a degradação dos recursos hídricos, do solo e do ar. A Associação Brasileira de Normas Técnicas (ABNT), 2004 (NBR 10004) define os resíduos sólidos como os originários de atividades agrícola, industrial, comercial, hospitalar e doméstica, que exigem soluções técnicas para o seu descarte adequado, dadas às suas peculiaridades, as quais os tornam danosos para a rede pública de água e esgoto, por exemplo.

A geração e o controle de resíduos produzidos nas empresas têm despertado grande interesse dos consumidores, fornecedores e produtores de um modo geral, com a finalidade de preservar o meio ambiente. Para tanto, é preciso que sejam implementadas ações para quantificar e caracterizar os resíduos industriais, de modo a definir os sistemas de tratamento ou de condicionamento mais adequados. Observa-se também um aumento nos estudos referentes à temática dos resíduos sólidos (DEUS; BATTISTELLE; SILVA, 2015). De acordo com Martins e Filho, (2010), as MPEs encontram barreiras para a adoção de práticas ambientais, o que leva muito autores a identificarem esse tipo de gestão como inviável, por hora, para esses tipos de empresas.

A gestão ambiental deve ser vista como alternativa real, a qual deverá ser utilizada por empresas de todo mundo, para melhorar e controlar suas atividades de forma a poluir menos o meio ambiente, com a finalidade de gera uma melhor economia. Consequentemente, maior competitividade, em função da modernização de projetos e de processos e da redução do desperdício. 


\subsection{Sustentabilidade}

O grande desafio da atualidade é promover o desenvolvimento sustentável, entendido como desenvolvimento capaz de satisfazer às necessidades presentes, sem comprometer as necessidades das futuras gerações. No entanto, o conceito de desenvolvimento sustentável vincula-se à preocupação com a manutenção e a existência de recursos naturais para a continuidade das gerações futuras. Apesar das economias apresentarem diferentes interpretações, elas deverão estar centradas no objetivo comum, que é inerente ao conceito de desenvolvimento sustentável, e nas estratégias necessárias para sua execução.

O desenvolvimento sustentável significa progresso, crescimento econômico e avanços científicos de forma a preservar o meio ambiente. Para que isso aconteça de forma prática, deve haver vários procedimentos, os quais devem ser tomados por pessoas, governos e empresas para não prejudicar a fauna, a flora e os recursos naturais disponíveis em nosso planeta. Quando isso ocorre, fica notória a garantia de uma existência sustentável de desenvolvimento que é de extrema importância para a sociedade, garantindo as condições ambientais favoráveis para as futuras gerações.

Na prática, a implementação desse conceito no negócio dá-se pela necessidade de enfrentar os desafios do século XXI, na raiz dos quais reside a consciência generalizada da profunda crise ecológica global. Desperta, assim, uma atenção especial às questões relacionadas com a qualidade ambiental e a exploração econômica de recursos (WITKOWSKI; SANIUK, 2010).

A preocupação com o meio ambiente faz com que logística reversa deva andar na mesma velocidade da sustentabilidade, com a finalidade de despertar em toda a sociedade uma conscientização ecológica. Dessa forma, espera-se que as empresas reduzam os impactos negativos sobre o meio ambiente, fruto do seu processo produtivo, realizando o tratamento e a recuperação dos resíduos produzidos (NASCIMENTO et al., 2015).

A sustentabilidade deve andar na mesma velocidade que a logística reversa, pois a preocupação com o meio ambiente aumenta a cada dia nas empresas e faz com que elas tenham uma gestão sustentável, que deve ter como principais fatores recursos naturais, humanos e financeiros. Fazendo isso, consequentemente, haverá uma melhoria na imagem institucional. 
A Comissão Mundial sobre Meio Ambiente e Desenvolvimento define desenvolvimento sustentável da seguinte forma: “[...] o desenvolvimento que atende às necessidades do presente, sem comprometer a capacidade das futuras gerações atenderem às suas próprias necessidades". A propósito, anota o professor José Carlos Barbieri (BARBIERI, 2008): “O conceito de desenvolvimento sustentável sugere um legado permanente de uma geração a outra, para que todos possam prover suas necessidades".

Uma sociedade sustentável deve, portanto, caminhar no sentido do desenvolvimento sustentável, equilibrando o crescimento econômico com a preservação do meio ambiente e a qualidade de vida. A principal dificuldade para a implantação e desenvolvimento de uma sociedade sustentável é o fator econômico. Muitas empresas, buscando baratear os custos de produção, optam por processos produtivos poluentes e não sustentáveis.

Para Tachizawa (2002, p. 73):

A responsabilidade social e ambiental pode ser resumida no conceito de 'efetividade', como alcance de objetivos do desenvolvimento econômico-social. Portanto, uma organização é efetiva quando mantém uma postura socialmente responsável. A efetividade está relacionada à satisfação da sociedade, ao atendimento de seus requisitos sociais, econômicos e culturais.

A sustentabilidade e a responsabilidade social são temas que têm ocupado de forma crescente as discussões dentro de governos, empresas e organizações em todo o mundo. São cada vez mais evidentes para a sociedade a função social das organizações e a relação de interdependência entre os sistemas econômico, social e ambiental.

A Região de Jundiaí apresenta alguns arranjos produtivos locais, os quais podem facilitar um desenvolvimento equilibrado nas suas três principais dimensões: econômica, social e ambiental. No entanto, é fundamental que o espaço geográfico onde estes arranjos estejam inseridos apresente bom desempenho nos indicadores de sustentabilidade desenvolvidos para medi-la nos espaços geográficos - municípios. Segundo Oliveira (2009), é a maneira como os diversos atores do cluster interagem entre si, e como isso afeta seus comportamentos e ações como entes individuais e como um coletivo. 


\section{Análise e resultados da pesquisa}

A pesquisa foi realizada no segundo semestre do ano de 2013 , e dela participaram 58 micro e pequenas empresas do setor metalúrgico da Região de Jundiaí, envolvendo os municípios de Jundiaí, Campo Limpo Paulista, Itupeva, Cabreúva, Jarinu, Louveira e Várzea Paulista, localizados no estado de São Paulo.

De acordo com o SEADE, em 2007, a aglomeração urbana de Jundiaí representou 2,7\% do PIB estadual. É uma região predominantemente industrial, cujos municípios de Jundiaí e Louveira têm um perfil industrial relevante no estado, enquanto os demais classificam-se com perfil industrial - exceto Jarinu, com perfil de serviços. O município-sede destaca-se por sua indústria diversificada, relevando-se os setores de alimentos e bebidas, cerâmica, metal mecânica, autopeças, borracha, plásticos e embalagens. No setor de serviços, destacam-se os centros logísticos e o comércio atacadista de alcance nacional.

A seguir, foram demonstradas graficamente as respostas dadas às perguntas mais significativas do questionário devidamente aplicado.

Questão 1 - O ponto principal da logística reversa é cuidar do produto após a sua utilização, fazendo com que ele seja reutilizado, diminuindo custos e impactos ambientais, como contaminação do solo. $O$ resíduo industrial é um dos mais graves problemas ambientais. A logística reversa já foi implantada na sua empresa?

\section{Gráfico 1 - Implantação da logística reversa na empresa}

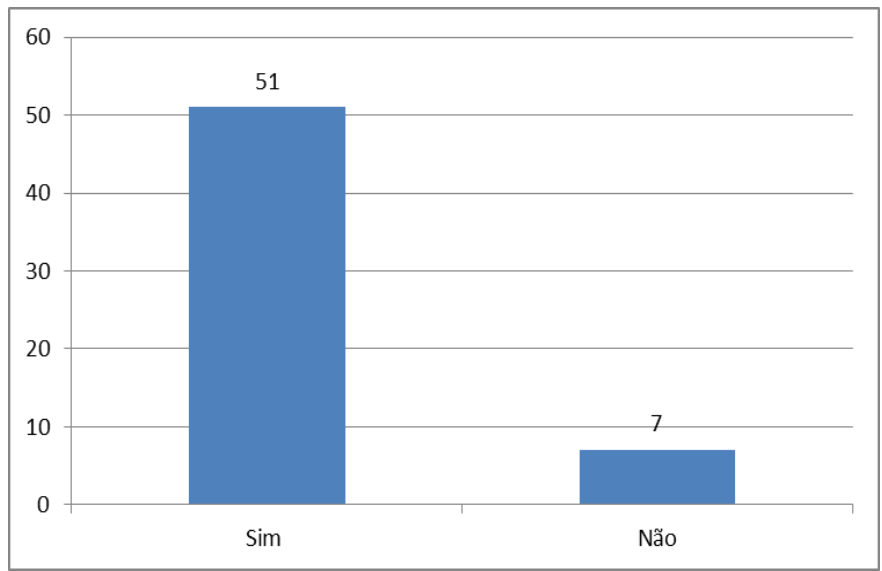

Fonte: Dados da pesquisa. 
Os dados demonstram que, das empresas pesquisadas, 87,93\% já implantaram a logística reversa, ou seja, já estão cumprindo a legislação em vigor, e que 12,07 \% ainda não a implantaram.

Questão 2 - Em média, qual a quantidade em Kg de resíduos sólidos que são produzidos por mês?

\section{Gráfico 2 - Média mensal de resíduos sólidos gerados}

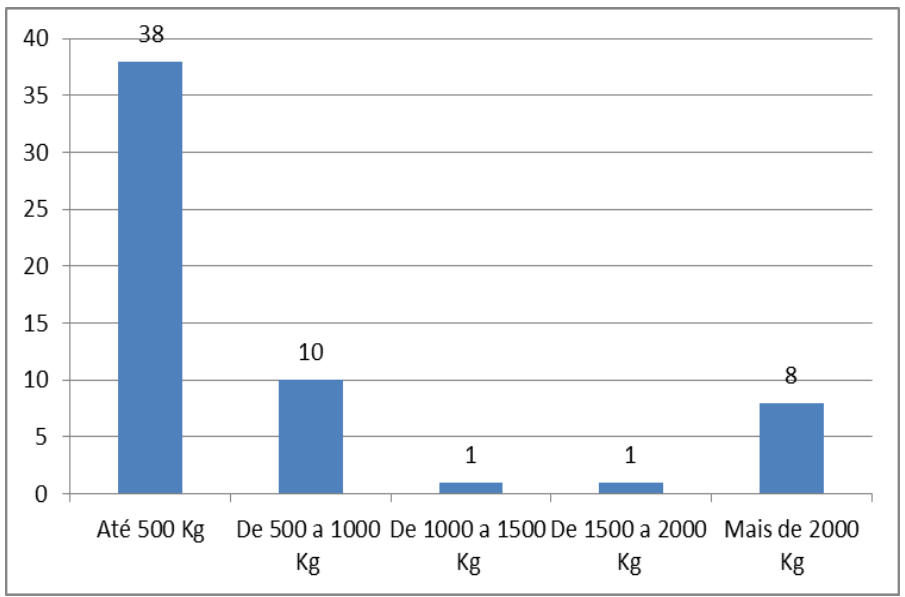

Fonte: Dados da pesquisa.

O uso de novas tecnologias mais "limpas" de produção contempla mudanças nos produtos e em seus processos de produção, para reduzir ou eliminar todo tipo de rejeito, antes que eles sejam criados.

Os dados demonstram que 65,52 \% das empresas produzem até $500 \mathrm{Kg}$ de resíduos sólidos no seu processo produtivo. Diante desses dados, é possível verificar que as empresas estão cada vez mais preocupadas com a produção mais limpa, a qual pode ser vista como uma estratégia de gestão que tem por foco a eficiência no uso de matéria-prima, energia, água e insumos, com o intuito de minimizar os impactos ambientais dos processos, serviços ou produtos. 
Questão 3 - A empresa tem tecnologia necessária para fazer a reciclagem dos seus produtos?

\section{Gráfico 3 - A empresa tem tecnologia para efetuar a reciclagem}

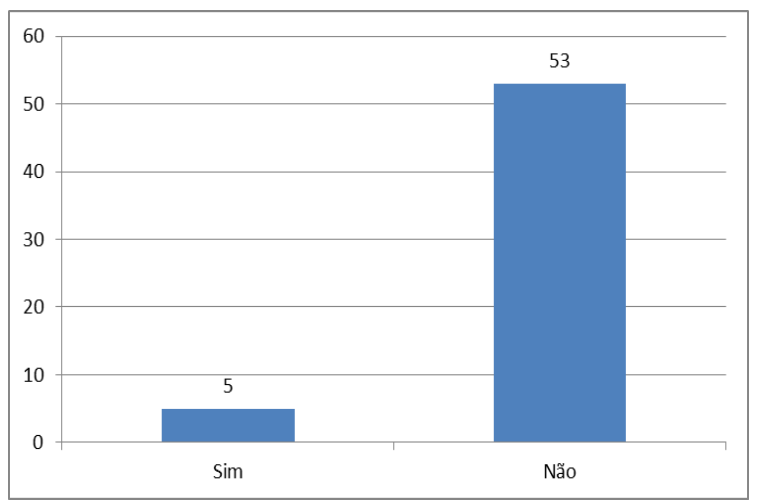

Fonte: Dados da pesquisa.

Tecnologia é um termo que envolve conhecimento técnico, científico e ferramentas, processos e materiais criados e/ou utilizados a partir de tal conhecimento. Os dados demonstram que apenas 8,62 \% possuem tecnologia para realizar a reciclagem dos resíduos gerados; 91,38 \% não possuem a respectiva tecnologia. A decisão sobre investimentos tecnológicos deve avaliar não somente se esta ou aquela tecnologia proporciona melhor valor agregado, mas, sim, as vantagens dessa tecnologia sobre a organização empresarial e seu impacto nos custos dos processos (RODRIGUEZ et al., 2016).

Questão 4 - Quais são os maiores desafios encontrados na implantação da logística reversa?

\section{Gráfico 4 - Desafios encontrados na implantação da logística reversa}

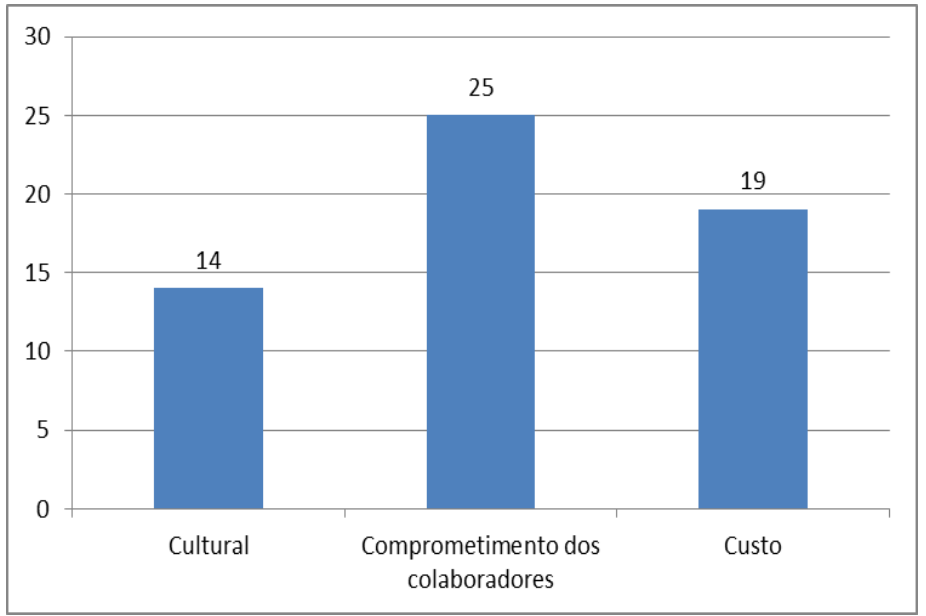

Fonte: Dados da pesquisa. 
Os dados demonstram que o aspecto cultural corresponde a $24,14 \%$; já o item comprometimento dos colaboradores equivale a $43,10 \%$, e o item custo corresponde a 32,76 \%. O desafio maior, como se pode ver, é o comprometimento dos colaboradores. Para que uma empresa tenha sucesso, é necessário haver o comprometimento de seus colaboradores.

Questão 5 - Com relação ao destino dado aos resíduos sólidos produzidos pela empresa, ela os disponibiliza para?

\section{Gráfico 5 - Destino dos resíduos sólidos}

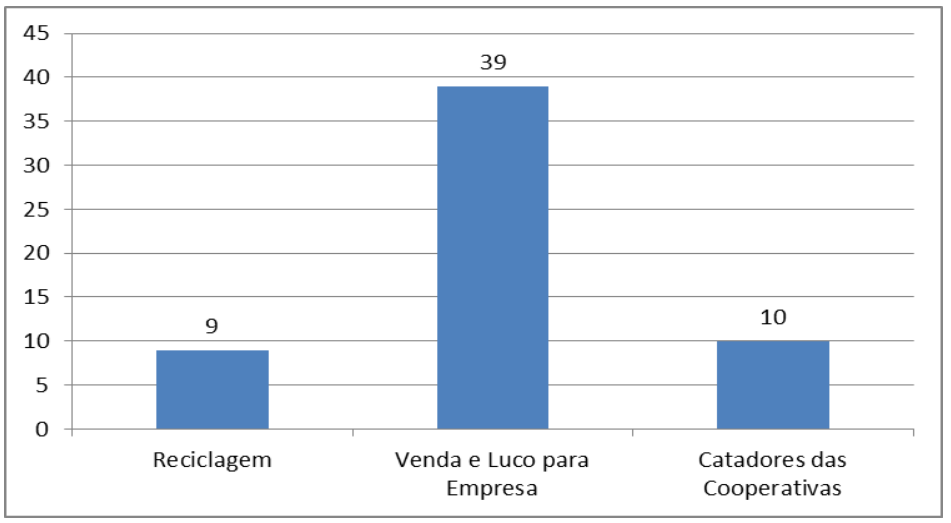

Fonte: Dados da pesquisa.

Os dados demonstram que o item venda e lucro representa para a empresa $67,24 \%$ do total, e o item reciclagem corresponde a $15,52 \%$, tendo em vista a maioria das empresas não terem tecnologia suficiente para realizar a reciclagem.

Questão 6 - Quais as principais razões que levam as empresas a atuarem em logística reversa?

\section{Gráfico 6 - Razões que levam as empresas implantarem logística reversa}

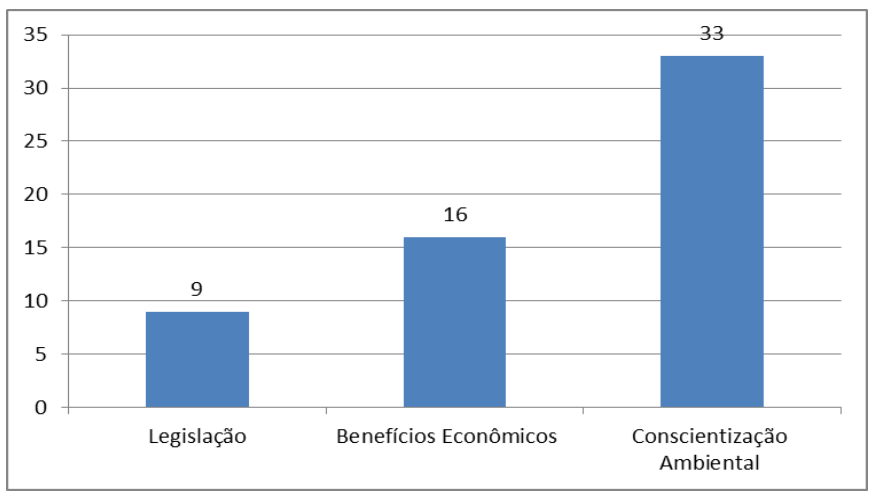

Fonte: Dados da pesquisa. 
Os dados demonstram que o item conscientização ambiental representa $56,90 \%$ do total. Dessa forma, é possível verificar que existe uma preocupação com a preservação e a utilização sustentável dos recursos naturais do nosso planeta.

Questão 7 - Sua empresa faz investimentos em ações relacionadas ao tratamento de resíduos sólidos?

\section{Gráfico 7 - A empresa faz investimentos no tratamento de resíduos}

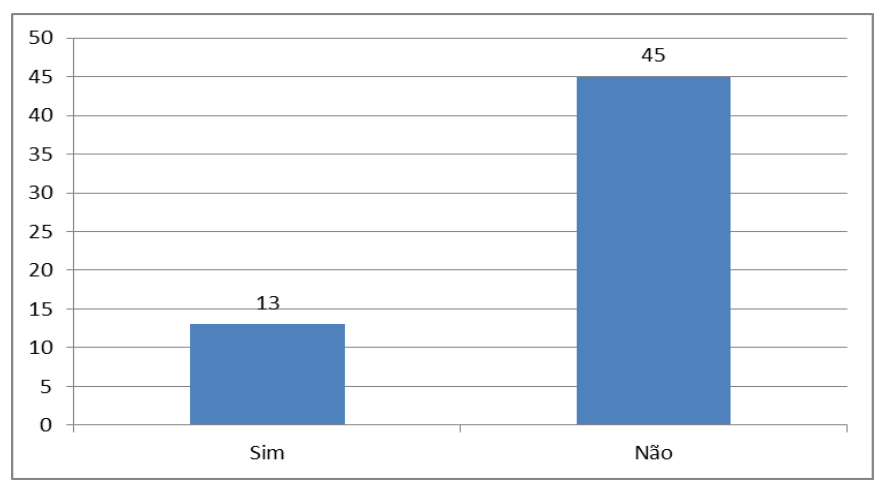

Fonte: Dados da pesquisa.

Os dados demonstram que 77,59 \% das empresas não fazem investimentos para o tratamento de resíduos sólidos, tendo em vista a pequena quantidade de resíduos gerados no processo produtivo. Sendo assim, as empresas preferem vender os resíduos para a obtenção de lucro. 
Questão 8 - A empresa possui a certificação ISO 14000, que compreende uma série de normas desenvolvidas pela International Organization for Standardization (ISO), as quais estabelecem diretrizes sobre a área de gestão ambiental dentro de empresas?

\section{Gráfico 8 - A empresa possui a Certificação ISO 14000}

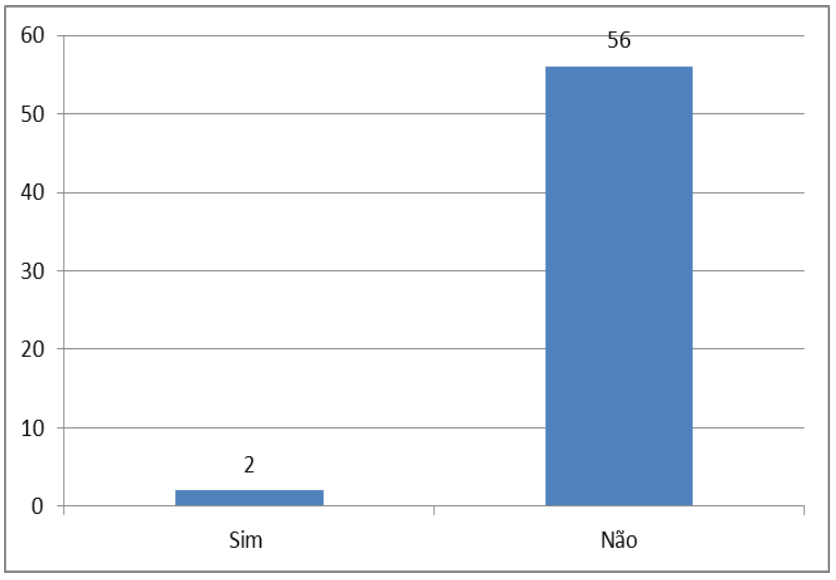

Fonte: Dados da pesquisa.

O ISO 14000 é um conjunto de normas que definem para as empresas (privadas e públicas) parâmetros e diretrizes para a gestão ambiental. Estas normas foram definidas pela International Organization for Standardization - ISO (Organização Internacional para Padronização), tendo como objetivo diminuir o impacto provocado pelas empresas ao meio ambiente. Muitas empresas utilizam recursos naturais, geram poluição, ou causam danos ambientais por meio de seus processos de produção. Seguindo as normas do ISO 14000, elas podem reduzir significativamente esses danos ao meio ambiente.

Os dados demonstram que $96,55 \%$ das empresas não possuem o ISO 14000, e apenas 3,45 \% delas possuem a referida certificação. Um dos motivos pela não implantação está no custo, pois não é barato implementar numa empresa a certificação ISO 14000.

A respectiva norma tem que ser vista como uma ferramenta para auxiliar as empresas na identificação, priorização e gerenciamento de seus riscos ambientais como parte de suas práticas usuais. A norma faz com que a empresa dê uma maior atenção às questões mais relevantes de seu negócio. A NBR ISO 14001 exige que as empresas se comprometam com a prevenção da poluição e com melhorias contínuas, como parte do ciclo normal de gestão empresarial. 
Questão 9 - A fiscalização dos órgãos governamentais relacionados à gestão de resíduos sólidos na empresa é: Frequente? Pouco aparece? Quase nunca aparece? Nunca aparece? Ou, não sabe?

\section{Gráfico 9 - Fiscalização dos órgãos governamentais}

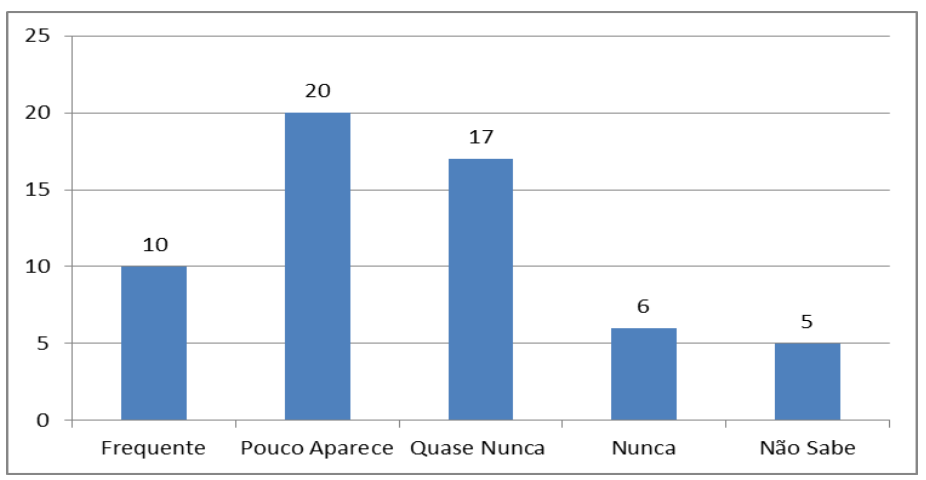

Fonte: Dados da pesquisa.

A importância da fiscalização é garantir que as exigências e condicionantes estabelecidas nos processos sejam cumpridas, além de também regularizar situações de irregularidades. Os dados do gráfico 10 demonstram que 34,48 \% dos gestores afirmam que a fiscalização pouco aparece, e 29,31\% afirmam que quase nunca aparecem. Nesse contexto, é possível verificar que a fiscalização ainda está inibida, sendo necessária uma maior presença por parte do Estado para que ela seja realizada de forma efetiva.

\section{Conclusões}

No ano de 2010, foi sancionada a Lei no 12.305 (BRASIL, 2010), que trata da Política Nacional de Resíduos Sólidos, a qual tem como finalidade atender aos apelos constitucionais e sociais, almejando soluções práticas e eficazes acerca da questão dos resíduos sólidos no país. Nesse contexto, uma das maiores mudanças introduzidas pelo diploma legal foi a responsabilidade ambiental em relação aos resíduos, deixando de ser exclusivamente do poder público e passando a ser compartilhada por toda a cadeia de consumo.

A logística reversa pode ser vista como uma ferramenta estratégica para abrir competitividade no mercado de atuação. No entanto, há alguns aspectos que precisam ser considerados para que essa logística cumpra este papel. A logística deve estar condicionada às decisões estratégicas das MPEs, ou seja, é necessário que parta da direção a iniciativa de explorar as oportunidades como forma de agregar valores no resultado final. Por intermédio 
da pesquisa realizada e das entrevistas com os gestores das MPEs, percebeu-se a importância de uma visão empreendedora, na qual ocorra a possibilidade do aproveitamento dos resíduos gerados pelo processo produtivo e, com isto, a geração de oportunidades para aumentar as receitas e se diferenciar da concorrência no mercado.

Foi possível verificar a necessidade de serem implementadas ações para quantificar e caracterizar os resíduos industriais, de modo a definir os sistemas de tratamento, como também o descarte final dos resíduos gerados durante o processo produtivo, para que esse descarte não ocasione problemas de poluição/contaminação ambiental. Sendo assim, a empresa estará cumprindo a legislação específica vigente e atendendo à expectativa da sociedade, além de evitar também futuros transtornos com ambientais.

A logística reversa apresenta-se como oportunidade de desenvolver a sistematização dos fluxos de resíduos, bens e produtos descartados, seja pelo fim de sua vida útil, seja por obsolescência tecnológica, bem como o seu reaproveitamento, contribuindo para a redução do uso de recursos naturais e demais impactos ambientais. O sistema logístico reverso consiste em uma ferramenta organizacional que viabiliza as cadeias reversas, de forma a contribuir para a promoção da sustentabilidade de uma cadeia produtiva.

Durante o estudo, foi possível perceber que as empresas têm grande interesse em implantar a logística reversa, mas nem todas estão ainda estruturadas para atender completamente a todos os requisitos necessários para essa implementação.

Conclui-se que a logística reversa pode ser explorada pelas empresas metal mecânicas, pois o metal é um dos produtos mais utilizados nas tarefas do dia a dia. Ele pode ser encontrado das mais diversas formas e em diversos produtos. Ao ser reciclado, ele tem praticamente todas as características do metal comum e pode ser reciclado muitas vezes sem perder suas características e qualidade.

Os micro e pequenos empresários entrevistados da Região de Jundiaí afirmam ter consciência de que as práticas reversas de logística são de grande importância para as organizações, no entanto eles têm dificuldades na implantação da logística reversa, uma vez que isso requer projetos específicos, com altos custos financeiros, além da falta de estrutura organizacional (pessoas e técnicos) para realizar de fato a implantação das práticas de logísticas reversas. 


\section{Referências}

ASSOCIAÇÃO BRASILEIRA DE NORMAS TÉCNICAS - ABNT (2004) Resíduos Sólidos Classificação NBR - 1004. Rio de Janeiro, ABNT. 71p. ABNT NBR 10004:2004. Disponível em: <http://www.aslaa.com.br/legislacoes/NBR\%20n\% 201000 4-2004.pdf>. Acesso em: 7 nov. 2013.

BARBIERI, J. C. Desenvolvimento e Meio Ambiente: as estratégias de mudanças da Agenda 21. 10. ed. Petrópolis: Vozes, 2008.

BRASIL. Congresso. Câmara dos Deputados. Lei no 12.305, de 2 de agosto de 2010. Institui a Política Nacional de Resíduos Sólidos; altera a Lei n 9.605, de 12 de fevereiro de 1998; e dá outras providências. Brasília, 2010. Disponível em: <http://www.planalto.gov.br/ccivil_03/ _ato2007-2010/2010/lei/l12305.htm>. Acesso em: 12 set. 2013.

CARVALHO, A. P.; BARBIERI, J. C. Inovações Socioambientais em Cadeias de Suprimento: um estudo de caso sobre o papel da empresa focal. RAl: Revista de Administração $e$ Inovação, v. 10, p. 232-256, 2013.

CENSOS DEMOGRÁFICOS DO IBGE 1900 A 2000. Projeções do IBGE de 2010 a 2050 (revisão 2008) e projeções próprias de 2050 a 2100. Disponível em: <www.ibge.gov.br>. Acesso em: 30 dez. 2012

DEUS, R. M.; BATTISTELLE, R. A. G.; SILVA, G.H. R. Resíduos sólidos no Brasil: contexto, lacunas e tendências. Engenharia Sanitária Ambiental, v. 20, n. 4, p. 685-698, 2015.

DOURADO, J.; SAIANI, C. C. S.; TONETO, R. Resíduos sólidos no Brasil: oportunidades e desafios da Lei Federal n 12.305 (Lei de Resíduos Sólidos). Barueri: Minha Editora, 2014.

JOHNSON, P. F. Gerenciando valor em Sistemas de Logística Reversa. Logística e Transporte Comente. v. 34. n. 3. p. 217-227, 1998.

KING, A. M. et al. Reducing waste: repair, recondition, remanufacture or recycle? Sustainable Development, v. 14, n. 4, p. 257-267, 2006.

LAKATOS, E. M.; MARCONI, M. de A. Fundamentos de metodologia científica. 6. ed. São Paulo: Atlas, 2009.

LEITE, Paulo Roberto. Logística reversa: meio ambiente e competitividade. São Paulo: Prentice Hall, 2003.

NASCIMENTO, V. F. et al. Evolução e desafios no gerenciamento dos resíduos sólidos urbanos no Brasil. Revista Ambiente e Água, v. 10, n. 4, p. 889-902, 2015.

OLIVEIRA, José Antonio Puppim (Org.). Pequenas empresas, arranjos produtivos locais e sustentabilidade. Rio de Janeiro: FGV, 2009. 
PANORAMA dos resíduos sólidos no Brasil 2014. ABRELPE 2013 e 2014. Disponível em: <http://www.abrelpe.org.br/Panorama/panorama2014.pdf>. Acesso em: 3 mar. 2016.

PORTAL DA SUSTENTABILIDADE. Disponível em: <http://www.sustentabilidade. org.br/>. Acesso em: 1 out. 2013.

RESENDE, E. L. Canal de distribuição reverso na reciclagem de pneus: estudo de caso. 2004. Dissertação (Mestrado em Engenharia de Produção) - Pontifícia Universidade Católica do Rio de Janeiro, Rio de Janeiro, 2004.

SEADE - Rede Urbana e Regionalização do Estado de São Paulo. Disponível em: <http://www.seade.sp.gov.br/produtos/publicacoes/pub_RedeUrbanaRegionalizacaoESP_2 011.pdf>. Acesso em: 11 mar. 2014.

TACHIZAWA, T. Gestão ambiental e responsabilidade social corporativa: estratégias de negócios focadas na realidade brasileira. São Paulo: Atlas, 2002.

VERGARA, Sylvia C. Projetos e relatórios de pesquisa em administração. 3. ed. São Paulo: Atlas, 2000.

WITKOWSKI, K.; SANIUK S. Aspectos de gestão de logística da infraestrutura da cidade. Internacional Logística e Supply Chain Congress 2010. Associação Logística Publicação n. 9, Istambul, Turquia, 2010.

ZIMERMANN, R. A.; GRAENL, A. R. Logística reversa - conceitos e componentes do Sistema. Estudo de caso: Teletex Computadores e Sistemas. XXII ENEGEP. Ouro Preto, out. 2003. 